\title{
CSR indicators proposed by GRI and its application to field of SMEs in Argentina
}

\author{
Estefanía Solari \\ Facultad de Ciencias Económicas - \\ Universidad Nacional de La Plata \\ Argentina \\ estefania.solari@econo.unlp.edu.ar
}

\author{
Laura Nelly Tavella \\ Facultad de Ciencias Económicas - \\ Universidad Nacional de La Plata \\ Argentina \\ Intavella56@gmail.com
}

\author{
Diana Pacheco Ortiz \\ Facultad de Ciencias Económicas y \\ Administrativas del Instituto Técnico \\ Metropolitano de Medellín \\ Colombia \\ dianapacheco@itm.edu.co
}

\begin{abstract}
The objectives of the following article are to perform a bibliographic review about the indicators proposed by the GRI for the measurement of CSR, its relation MDG and SDG. At the same time, the application of the indicators proposed by the GRI in the field of Argentine SMEs is analyzed. This article concluded fundamentally according to the information shown, that in Argentina, given that only $11 \%$ of the companies adhering to the GRI are SMEs, it is evident the importance of deepening the subject and of further compromising those who manage these companies. We propose, for future research, to deepen the design of a CSR management model that allows SME entrepreneurs to also actively participate in compliance with the SDG, thus contributing to the improvement of the quality of life of the whole humanity.
\end{abstract}

\section{Keywords- CSR, GRI, SDG, CSR Indicators, SMEs}

\section{INTRODUCTION}

The idea of this research is to deepen the subject of measuring the practices of Corporate Social Responsibility (CSR). It is worth mentioning that quantifying and objectifying them allows collaborating in the decision-making process of the interested parties through knowledge of the impact of the operation of the company in its social, environmental and economic environment. The issue has been addressed by academics, as well as by specific initiatives from which indicators of CSR measurement emerged, such as: the Global Reporting Initiative (GRI) and the Global Compact. This research will focus on an exploratory analysis on the subject.

The objectives of the work will be:

1- Carry out a bibliographic review about the indicators proposed by the GRI, contemplating the approach in each case for the measurement of CSR and its relationship with the 10 Millennium Development Goals (MDGs).

2- Analyze the relationship of the indicators proposed by the GRI and its relationship with the Sustainable Development Goals (SDG)

3- Analyze the application of the indicators proposed by the GRI in the field of Argentine SMEs (Small and Medium Enterprises).

\section{THEORETICAL FRAMEWORK}

In recent years, literature on CSR has proliferated, either describing actions, arguing about their need or presenting ways to understand it. Many definitions or descriptions have been proposed [1].

When defining what is meant by Corporate Social Responsibility (CSR) there is no general consensus, that is how from different areas definitions have been generated, all to be taken into account due to their respective impacts. It is for this reason that briefly, some contributions to the definition of CSR made from organizations promoting CSR practices, as well as some prominent authors on the subject, will be stated.

In the first place, the role of the Global Compact (United Nations) is worth mentioning, as follows: "The objective of the Global Compact is to promote social dialogue for the creation of a global corporate citizenship, which allows the conciliation of business interests with values and the United Nations mandate demanded by civil society, trade unions and governments. These values are translated into universal principles related to the defense of human rights, labor standards, the environment and the fight against corruption. The initiative aspires that companies adhere to them voluntarily and, gradually, incorporate them into the management of the business, so that they penetrate into their organizational culture and become a guide to link up with the different interest groups "[2].

In Argentina, the Argentine Institute of Corporate Social Responsibility (IARSE) was created in mid-2002 with the mission of "promoting and disseminating the concept and practice of CSR to promote the sustainable development of Argentina, working together with companies through information networks, exchange of experiences and mutual collaboration".

Starting from conceiving CSR as a management model that considers the economic, environmental, ethical and social impacts derived from business activity, the Institute creates value for companies and society by working together with the business world, generating management tools and information mechanisms and exchange of experiences. It also promotes mutual collaboration between companies that have decided to make their responsible behavior a value from which to contribute to the construction of a more just and sustainable society [3].

On the other hand, in the academic environment many authors have investigated the issue and defined the concept of CSR. 
Although there are different definitions, it is worth highlighting the way in which Izquierdo, J.A.M. [4] defines it as: "the free will of the company to provide the greatest possible value to its different interest groups". A seemingly simple definition, but that involves many implications.

From this definition the following ideas come off:

- First of all, that it is a will that is not bound by legal imperative. Although well understood CSR requires scrupulous compliance with the law, the good practices that it gives rise to must exceed the legal requirements (otherwise, we would be facing the simple legal responsibility).

- Secondly, that the will to contribute value (of profit to some extent) to each stakeholder is conditioned by the parallel willingness to treat with similar criteria to the rest. With this, it is only possible to properly understand CSR from a global perspective and presided over by the reiterated principle of balance.

- It is a principle that leads to a third implication: this measured attention to all stakeholders means taking into consideration all the dimensions of the company's activity (financial, commercial, legal, labor, etc.).

In this research emphasis will be placed on CSR practices, considering that given: "What is not measured is not managed", then it is essential to develop indicators for the measurement of CSR practices.

It is for this reason, that management indicators are needed that, in the manner of a compass, help to ensure compliance with the strategy -the north followed- and even integrate the principles or aspects of CSR and personal performance [5].

It is important to conceptualize the definition of "indicator", according to the Inter-American Development Bank (IDB), 2016, it can be said that the indicators come from the concepts that researchers and policymakers are trying to measure. Theories are constructions of interrelated concepts that, in the neopositivist paradigm of knowledge, must be made "observable". To achieve the latter, it is necessary to operationalize these concepts in dimensions; and those dimensions will be divided into variables, which, in turn, will be measured with indicators. Statistically, the variables can be classified as qualitative or quantitative (continuous or discrete), since the characteristics of these variables are different, as is their scale of measurement. It should be added that the statistical procedures vary according to the scales of measurement in which the data can be expressed.

On the other hand, the data alone do not constitute an indicator; they are lists of characteristics of populations; "accounts" or "magnitudes" that are hardly used as initially presented. The indicators are, in general, the relationship between two or more variables [6]. Statistically different measures are used for the construction of indicators, among them: the average, ratios, proportions, rates, etc.

It is also important to mention the contribution of Cabrera H. \& González Navarro[7], according to this author the indicators must meet three requirements. First, the indicator must be reliable, that is, offer the same possible answers when applied more than once. Secondly, the indicator must be comparable over time and between different companies, offering a homogeneous result, which facilitates the creation of a CSR ranking among, for example, companies within the same sector. Finally, an indicator must be valid, that is, it must be capable of measuring those for which it was built, the CSR practice that it seeks to measure.

Since the indicators proposed by the GRI were addressed, it is important to mention in what context it emerged, at the end of the 1990s, how to solve a major problem was debated: although for the preparation of financial reports of the organizations there were a series of internationally accepted guidelines, the same did not happen when verifying the economic, environmental and social aspects of these organizations. Some of them, from different contexts proposed a set of quantification systems and guidelines to carry it out, focusing on specific issues of the economic, environmental or social.

A coalition led by CERES (Coalition for Environmentally Responsible Economies) and UNEP (United Nations Environment Program) decided to take on this task and seek a solution through an intensive process of consultations with companies, NGOs, experts and other international institutions dedicated to social and environmental issues. Based on this initiative, the first version of the Global Reporting Initiative Guide was prepared in 2000. This was possible thanks to the participation and dedication of a large number of people and organizations committed to defending sustainability, transparency and accountability. The result of these efforts was that GRI became an independent organization in 2002. It was set up with the mission "that the process of preparing sustainability reports become as common as that of financial reports", and It also established the guarantor of the Guide and of its process of realization [8].

\section{METHODOLOGY}

The research methodology used in this paper was bibliographic research, collection of secondary data in digital compendiums and analysis of the reports of the CSR evaluation, which allowed us to analyze the model proposed by the GRI and its link with Development Objectives of the Millennium (MDG), as well as the Sustainable Development Goals (SDGs). On the other hand, to analyze their use in the field of Argentine SMEs, in April 2016, Argentine companies adhering to the GRI were released according to their size and a frequency tables were made.

\section{RESULTS}

\section{A. .Indicators developed by the GRI}

In the first place, it is noteworthy that according to the GRI, the preparation of sustainability reports helps organizations to set objectives, measure performance and manage change in order to make their operations more sustainable. Sustainability reports contain information on the impact of organizations, whether positive or negative, on the environment, society and the economy. It is these sustainability reports that contain the 
indicators for monitoring CSR practices. Another substantial contribution of the sustainability reports originates when the content and measurement systems are agreed at an international level, since this favors the accessibility and comparability of the information, and consequently, improves the quality of the information so that the groups of interest take the pertinent decisions [9].

The framework for the preparation of Sustainability Reports of the GRI was created to facilitate a "common language" that could be applied by all types of organizations and has been drafted with reference to a large number of international agreements and standards. This is how the GRI G3 Sustainability Reporting Guide refers, as far as possible, to generally accepted laws and norms [8].

At the time of preparing the Reports according to the G3 Guide, companies are allowed to choose the level at which they want to make the memory (from $\mathrm{C}$, for beginners, to $\mathrm{A}+$ for the most experienced), which reflects the different grades of the GRI Framework.

Then, the GRI G4 Guide was created, and it is established that all the reports that will be published after December 31, 2015 must be prepared "in accordance" with the latter. Thus, if the organization discloses a series of basic contents described in the Guide but does not meet all the requirements of the "conformance" options, the following clarification must be included in the report: "In this report, basic contents of the Guide for the preparation of GRI reports ". At the same time, the guide for preparing G4 reports establishes that those organizations that wish to prepare their sustainability reports "in accordance" with the Guide have two options: the Essential option and the Comprehensive option. All organizations, regardless of their size, sector or location, can apply any of the options. The Essential option consists of the fundamental elements of a sustainability report; it constitutes a framework through which organizations transmit the consequences of their economic, environmental, social and government performance. The Exhaustive option develops the Essential, to which it incorporates new basic contents related to the strategy, analysis, governance, ethics and integrity of the organizations. In addition, they must describe their performance in a more detailed way, for which they have to cover all the indicators related to the material aspects.

In this way, the indicators proposed by the GRI offer information on the performance or economic, environmental and social effects of the organization in reference to its material aspects. The material aspects are those that reflect the significant economic, environmental and social impacts of the organization, or those that have a significant weight in the evaluations and decisions of the stakeholders.

The 10 MDGs proposed by the Global Compact are all included in the categories and indicators proposed by the GRI, therefore a company that prepares the sustainability reports according to the standards proposed by the GRI, is also contributing to the achievement of the 10 MDGs proposed in the year 2000 by the Global Compact.

\section{B. From the MDGs to the SDGs}

Between 2000 and 2015, the MDGs provided an important development framework and achieved success in a number of areas, such as poverty reduction and improvement in health and education in developing countries [10].

The SDGs replace the MDGs, broadening the challenges that must be addressed to eliminate poverty and encompassing a wide range of interconnected issues across the economic, social and environmental dimensions of sustainable development.

On September 25, 2015, world leaders adopted a set of global goals to eradicate poverty, protect the planet and ensure prosperity for all as part of a new sustainable development agenda. Each objective has specific goals that must be achieved in the next 15 years.

To achieve these goals, everyone has to do their part: governments, the private sector and civil society. Hence the importance of the incorporation of CSR practices by companies that contribute to the achievement of the SDGs.

Thus, although the SDGs have governments as their main recipients, they recognize the fundamental role that companies can and should play in achieving those objectives. Here are the 17 SDGs:

- Goal 1: No Poverty

- Goal 2: Zero Hunger

- Goal 3: Good Health and Well-Being

- Goal 4: Quality Education

- Goal 5: Gender Equality

- Goal 6: Clean Water and Sanitation

- Goal 7: Affordable and Clean Energy

- Goal 8: Decent Work and Economic Growth

- Goal 9: Industry, Innovation and Infrastructure

- Goal 10: Reduced Inequalities

- Goal 11: Sustainable Cities and Communities

- Goal 12: Responsible Consumption and Production

- Goal 13: Climate change

- Goal 14: Life Below Water

- Goal 15: Life on Land

- Goal 16: Peace, Justice and Strong Institutions

- Goal 17: Partnerships for the Goals

Observing the 17 objectives, it is clear how organizations through their different activities can and should contribute to them, hence the importance of the generation of CSR practice measurement indicators aligned with the SDGs. 


\section{Relationship between the GRI and the SDGs}

It is worth emphasizing that the SDGs in goal 12.6 ask governments around the world to "Encourage companies, especially large companies and transnational corporations, to adopt sustainable practices and incorporate information on sustainability in their presentation".

In turn, the report prepared by the Sustainable Development Goal [10] states that it is of fundamental interest that companies use internationally recognized standards for their sustainability reporting processes, such as the exhaustive standards offered by GRI and / or information mechanisms at the aspect level such as those of the CDP and others.

In this way, it can be observed that several of the principles established by the GRI become even more important and feasible with the arrival of the SDGs.

\section{Argentine SMEs and GRI indicators}

According to the GRI (2012), the process of preparing GRI reports has been specially designed to be suitable for all types of organizations, not just large companies. In this way, for some authors like Moneva, JM, \& Ortas, E.[11]., they consider that each time there are more and more SMEs that find incentives to carry out CSR practices, and that this increase has been favored for the offer of the "High 5 " resource of the GRI (framed within the scope of the 2002 guide), which aims to promote the development of sustainability reports by SMEs. Additionally, and with the aim of adapting the G3 Guide, the GRI developed a manual intended only for SMEs.

However there are various opinions from the academy about the feasibility of applying the indicators proposed by the GRI in the field of SMEs, as opposed to the previous Vintro Sanchez, C. et. Al. [11]consider that although the measurement system proposed by the GRI is applicable to any company, in some cases the necessary data could be difficult to obtain or even, the number of criteria be excessive in relation to the size of the company. This is how they propose that to measure the degree of development of CSR practices, it would be more convenient to use a more operational and simplified Command Board.

The contribution of Herrera Madueño, J. et. Al. [13] who after a bibliographical analysis, contribute to glimpse that although in the field of large companies the public exposure of the same plays a fundamental role for the implementation of CSR practices, in the case of SMEs The main accelerator happens to be the ethical beliefs of the owner manager. However, what is mentioned as small companies resemble large companies, corporate characteristics such as size or sector will have a greater impact on the adoption of sustainable behavior.

To analyze in Argentina the level of application of the indicators proposed by the GRI in the SMEs, an information base was drawn up in April 2016, selecting Argentine companies adhering to the GRI and analyzing the variable size. From the selection emerged a base that had 119 Argentine companies adhered to the GRI.

Table I shows the Argentine companies adhering to the GRI by size, it can be clearly seen how most of them are large and multinational companies, and only $11 \%$ are small and medium-sized companies.

TABLE I. SIZE OF ARGENTINE COMPANIES ADHERING TO THE GRI

\begin{tabular}{|l|r|r|}
\hline Size & Quantity & Percentage \\
\hline Small and medium $<250$ employees & 13 & 10,9 \\
\hline Bigs $>=250$ employees & 76 & 63,9 \\
\hline Multinationals $>=250$ employees & 30 & 25,2 \\
\hline Total & 119 & 100,0 \\
\hline
\end{tabular}

Source: own elaboration

\section{DISCUSSION}

After the following analysis we emphasize that there is a committed and explicit work about how to define which are the indicators that measure the sustainable development of nations and companies in particular. Clear measurement tools have been developed, agreeing in the different areas which are the sustainability objectives and which would be the indicators that can measure them.

Starting from the fact that in societies in general there is a clear need for transparency and social, environmental and economic development worldwide and highlighting that what is not measured is not administered, it is fundamental if the indicators analyzed are applicable to all types of organizations.

In reference to Argentina, according to the information released, given that only $11 \%$ of the companies that adhere to the GRI are SMEs, it is clear that it is important to deepen the topic and to commit even more to who manages these companies.

On the other hand, it should be noted that SMEs in Argentina generate $44 \%$ of the wealth (excluding the agricultural sector) and generate $51 \%$ of employment [14], so it must be a great concern and a research initiative, to contribute to the measurement of CSR practices in their scope.

In this regard we adhere to some authors [12][13] who consider that the application of all the indicators proposed by the GRI or other similar initiatives in the The scope of SMEs can sometimes be very cumbersome and difficult to apply, hence we believe that a simple model should be developed, covering the main axes of sustainable development, based on the objectives of the Global Compact and the GRI, but defining a more limited number of indicators and easier follow-up for SMEs, that is, we propose for future research to deepen the design of a minimum model that allows SME entrepreneurs to commit to the issue, and this way to begin to develop habits, customs, in short a cultural change, that adheres to sustainable development in general, so that SMEs also participate actively in the fulfillment of the SDGs, thereby contributing to the improvement of the quality of life of all mankind.

\section{REFERENCES}

[1] Carné, D. M. (2007). Responsabilidad social de la empresa: una revisión crítica a las principales teorías. Ekonomiaz: Revista vasca de economía, (65), 50-67

[2] Liarte-Vejrup, N. (2015). El desafío de la sustentabilidad corporativa: una década de contribuciones del Pacto Global en Argentina/ilustrado 
por Verónica Grandjean. - 1a ed. - Buenos Aires: Programa Naciones Unidas para el Desarrollo - PNUD, 2015.E-Book.

[3] IARSE (2014). Anuario evolución 2014. Disponible en: https://issuu.com/iarseevolucion/docs/anuario_evoluci_n_iarse_2014. Recuperado el 19 de Septiembre de 2017).

[4] Izquierdo, J. Á. M. (2004). Responsabilidad social corporativa y competitividad: una visión desde la empresa. Revista valenciana de economía y hacienda, 12, 9-50.

[5] Perera, L. (2011) Indicadores para la gestión de la RSE en Vives, A., \& Peinado-Vara, E. LA RESPONSABILIDAD SOCIAL DE LA EMPRESA EN AMÉRICA LATINA. Publicación del Banco Interamericano de Desarrollo

[6] BID (2016). INDES. Indicadores para el desarrollo. Cadenas de Objetivos e Indicadores.

[7] Cabrera, H. S., \& González Navarro, M. (2014). Un Índice de Responsabilidad Social Empresarial para la Industria Salmonicultora en Chile. Revista Interamericana de Ambiente y Turismo-RIAT, 9(2), 5268.

[8] GRI (2012). La elaboración de memorias de sostenibilidad de GRI: ¿Vale la pena el viaje?

[9] GRI (2013). Guía para la elaboración de Memorias de Sostenibilidad.
[10] SDG. La guía para la acción empresarial en los SDG (2016). GRI, el Pacto Global de las Naciones Unidas y el WBCSD. Disponible: http://sdgcompass.org/wpcontent/uploads/2016/06/SDG_Compass_Span ish-one-pager-view.pdf (recuperado el 15 de Octubre de 2017)

[11] Moneva, J. M., \& Ortas, E. (2009). Desarrollo sostenible e información corporativa. Evolución y situación actual. Economía Industrial, 371, 139-154.

[12] Vintró Sánchez, C. Comajuncosa Casabella, J. C., \& Trench, M. T. (2009, April). Propuesta de un sistema de indicadores de responsabilidad social corporativa. In XIII Congreso de Ingeniería de Organización (pp. 1993-2003).

[13] Herrera Madueño, J., Larrán Jorge, M., \& Martínez-Martínez, D. (2013). Relación entre responsabilidad social y performance en las pequeñas y medianas empresas: Revisión bibliográfica. Cuadernos de gestión, 13(2).M. Young, The Technical Writer's Handbook. Mill Valley, CA: University Science, 1989.

[14] Fundación Observatorio Pyme (2016). Evolución reciente, situación actual y desafíos para el 2017. Disponible en : http://www.observatoriopyme.org.ar/newsite/wpcontent/uploads/2016/1 0/Informe-FOP-2015-16_Baja.pdf (Consultado el 10/10/2017). 